\title{
Interleukin-6 trans-signalling differentially regulates proliferation, migration, adhesion and maspin expression in human prostate cancer cells
}

\author{
Department of Urology, Innsbruck Medical University, Anichstrasse 35, A-6020 Innsbruck, Austria \\ (Correspondence should be addressed to I T Cavarretta; Email: ilaria.cavarretta@i-med.ac.at) \\ *(F R Santer and K Malinowska contributed equally to this work) \\ ${ }^{\dagger}$ (Z Culig and I T Cavarretta joint senior authorship)
}

Frédéric R Santer ${ }^{*}$ Kamilla Malinowska*, Zoran Culig ${ }^{\dagger}$ and Ilaria T Cavarretta ${ }^{\dagger}$

\begin{abstract}
Interleukin-6 (IL-6) is suggested to have a pathogenic role in the progression of prostate cancer (PC), therefore representing an attractive target for new therapies. However, due to the pleiotropy of this cytokine, targeting IL-6 results in different and unpredictable responses. In order to better understand the mechanisms underlying the different responses to the cytokine, we focused our attention on IL-6 receptors (IL-6Rs) that represent the first element in the cascade of cytokineactivated signalling pathways. IL-6 signal transduction may indeed occur through the membrane IL-6R (classical signalling) and/or through the less studied soluble IL-6R (sIL-6R; IL-6 transsignalling (IL-6TS)). We provide the first evidence how responses to IL-6 may depend on the different content of IL-6Rs in PC. In particular, the studies of ${ }^{3} \mathrm{H}$-thymidine incorporation and exploitation of different approaches (i.e. activation or inhibition of IL-6TS in sIL-6R-negative and -positive cell lines and transfection of IL-6R siRNA) allowed us to demonstrate that IL-6TS specifically accounts for an anti-proliferative effect of the cytokine in three PC cell lines that are known to respond differently to IL-6. Additionally, by applying migration-, scratch- and adhesion assays, we show that IL-6TS increases motility and migration and decreases adhesion of prostate cells facilitating thereby processes that determine metastasis initiation and spread. Finally, by western analyses, we uncovered an IL-6- and sIL-6R-dependent downregulation of the tumour suppressor maspin. Collectively, these data suggest that selective targeting of IL-6TS might allow to refine the currently available experimental anti-IL-6 therapies against PC.
\end{abstract}

Endocrine-Related Cancer (2010) 17 241-253

\section{Introduction}

Prostate cancer (PC) is one of the most common cancers in the western world. When the tumour is organ confined, radical prostatectomy or radiotherapy can in most cases cure the disease. In contrast, advanced stages of the tumour, after regression obtained with androgen ablation therapies, eventually develop a therapy-refractory phenotype. Median survival of men with therapy-resistant metastatic PC is limited to only 1-2 years; at this stage of the disease, the attempts to delay tumour progression have so far resulted in only a few months prolongation of survival (Petrylak 2007, Friedman et al. 2008, Lassi \& Dawson 2009). A better understanding of the mechanisms responsible for recurrence of the tumour is the basis for any possible therapeutical improvement.

Interleukin-6 (IL-6), a cytokine known as mediator of immunological and inflammatory events, has been shown to have a role in the development and progression of several types of tumours (Trikha et al. 2003, Mumm \& Oft 2008). In particular, clinical observations have documented increased IL-6 levels in plasma from patients with therapy-resistant metastatic 
disease compared to patients with earlier stages of the disease and healthy individuals (Twillie et al. 1995, Shariat et al. 2001, George et al. 2005). In vitro and in vivo studies suggested a pathogenic role of this cytokine in the progression of PC (Lin et al. 2001, Steiner et al. 2003, 2006, Cavarretta et al. 2007, Malinowska et al. 2009). In particular, an anti-IL-6 therapy was shown to be effective in inducing apoptosis and regression of androgen-dependent prostate xenografts in nude mice and the following inhibition of the conversion to an androgenindependent phenotype (Wallner et al. 2006). Although IL-6 represents a promising potential therapeutic target, biological responses to IL-6 and/or anti-IL-6 treatment are pleiotropic in various PC cell lines and xenografts confirming the complexity of the IL-6 action (Naka et al. 2002).

IL-6 binds to its specific receptor, IL-6 receptor $\alpha$ (IL-6R), a $80 \mathrm{kDa}$ glycosylated transmembrane protein belonging to the cytokine receptor superfamily. The complex IL-6/IL-6R associates with the protein gp130, a transmembrane cytokine receptor, thereby inducing gp130 dimerisation and initiation of signal transduction mainly through the Janus kinase/signal transducers and activators of transcription (STAT), phosphotidylinositol 3-kinase/Akt and mitogen-activated protein kinase pathways.

Neither IL-6 nor IL-6R alone is capable of binding to and activating gp130. However, a naturally occurring soluble form of IL-6R (sIL-6R), derived either by alternative splicing or by shedding of the membranebound IL-6R (mIL-6R), is able to bind the cytokine. The complex IL-6/sIL-6R activates gp130 also in the absence of the mIL-6R. This kind of signal transduction is named IL-6 trans-signalling (IL-6TS). The IL-6/sIL-6R complex may therefore potentiate the signal transduced by the mIL-6R or activate it in cells that do not express the receptor (Rose-John 2003). The gp130 subunit can also exist in a soluble form named sgp130. sgp130 has been shown to exclusively inhibit activation of the complex IL-6/sIL-6R without interfering with the complex IL-6/mIL-6R (Jostock et al. 2001). Classical and IL-6TS are thought to act in concert in mediating the response to IL-6. However, lately, it became evident that IL-6TS has a major relevance in the pathogenesis and development of chronic inflammatory diseases (Scheller \& Rose-John 2006, Nowell et al. 2009), as well as in colon cancer and melanoma (Jones et al. 2001, Kallen 2002, Becker et al. 2004, Mitsuyama et al. 2006b, Kang et al. 2007, Wagley et al. 2007, Nowell et al. 2009). Preclinical data suggest the possibility to improve current therapies by specifically inhibiting the sIL-6R (Nowell et al. 2003,
Mitsuyama et al. 2006a, Rose-John et al. 2007). Whether classical and IL-6TS pathways may be able to transduce specific events in PC is not known yet.

It has been reported that in a large cohort of patients with clinically localised PC, the preoperative serum levels of IL-6 and sIL-6R are higher in those who will develop metastases compared to individuals who will not experience recurrence of disease in the following 5 years (Kattan et al. 2003, Shariat et al. 2008). Interestingly, sIL-6R showed a stronger association with disease progression than IL-6, suggesting a role for sIL-6R in mediating specific cytokine effects and the spread of metastases. However, no data proving this hypothesis are so far available in PC.

In this study, we asked whether the effects of IL- 6 on PC cell proliferation are dependent on the preferential activation of its membrane or the soluble receptor and whether IL-6TS may play a role in processes that facilitate metastasis formation.

\section{Materials and methods}

\section{Cell lines and chemicals}

EP156T cells (human normal prostate epithelium, immortalised with hTERT) (Kogan et al. 2006) were grown in modified MCDB153 (Biological Industries, Kibbutz Beit Haemek, Israel) supplemented with 5\% FCS (PAA Laboratories, Pasching, Austria), $50 \mathrm{mg} / \mathrm{l}$ bovine pituitary extract (Invitrogen), penicillin/ streptomycin, $5 \mu \mathrm{g} / \mathrm{l}$ epidermal growth factor (PeproTech, Rocky Hill, NJ, USA) and $10 \mathrm{nM}$ of the synthetic androgen methyltrienolone R1881 (New England Nuclear, Dreieichenhein, Germany). LNCaP, PC3, Du145 (PC cells derived respectively from lymph node, bone and brain metastases), 22Rv1 (Sramkoski et al. 1999) and BPH-1 (Hayward et al. 1995) were grown in RPMI 1640 (PAA Laboratories) supplemented with $10 \%$ FCS, penicillin/streptomycin and $2 \mathrm{mM}$ GlutaMax. LAPC4 (lymph node metastatic PC cells) were grown in Iscove's Modified Dulbecco's Medium (IMDM) supplemented with $15 \%$ foetal bovine serum (HyClone, Szabo Scandic, Vienna, Austria) and $10 \mathrm{nM}$ R1881. LNCaP, PC3 and Du145 were obtained by the American Type Culture Collection (Manassas, VA, USA). BPH-1 and 22Rv1 cells were a kind gift from Dr Jack Schalken (University Medical Center St Radboud, Nijmegen, The Netherlands), and LAPC4 cells were kindly provided by Dr Charles Sawyers (University of California, Los Angeles, CA, USA). Recombinant human IL-6 and gp130/Fc Chimera (i.e. sgp130) were purchased from R\&D Systems (Wiesbaden, Germany), and CD126 (sIL-6R) was 
purchased from PromoKine (Heidelberg, Germany). Polyclonal goat maspin (C-20) antibody was purchased from Santa Cruz Biotechnologies (Santa Cruz, CA, USA) and monoclonal mouse glyceraldehyde-3-phosphate dehydrogenase (GAPDH) (6C5) antibody was purchased from Chemicon (Millipore, Billerica, MA, USA).

\section{sIL-6R and sgp130 ELISA}

Cells were seeded onto 6-well plates in their respective medium containing 3\% (v/v) charcoal-stripped serum (CSS). After $72 \mathrm{~h}$, sgp130 and sIL-6R levels were assessed with the human CD130/gp130 ELISA Kit and the CD126/IL-6R/gp80 ELISA Kit (both from Diaclone, Stamford, CT, USA) according to the manufacturer's protocol. Results were normalised to cell number in the respective well.

\section{RT-PCR}

Experimental conditions for RT-PCR were previously described (Malinowska et al. 2009).

\section{Treatments}

Treatments were performed in medium containing 3\% CSS. Soluble receptors were added at the concentrations indicated in each figure prior to exposure of cells to the cytokine. Du145, LNCaP and EP156T cells were treated with $5 \mathrm{ng} / \mathrm{ml}$ IL-6. Based on a previous publication (Malinowska et al. 2009), LAPC4 were treated with $25 \mathrm{ng} / \mathrm{ml}$ IL-6.

\section{siRNA transfections}

Cells were seeded onto 96-well or 6-well plates and transfected on the next day with 5 or $25 \mathrm{nM}$ IL-6R siRNA On-target Plus Smart Pool IL-6Ralpha or negative siRNA Control On-Target Plus Non-targeting Pool (Dharmacon, Lafayette, CO, USA) by using Lipofectamine 2000 (Invitrogen) in 3\% CSS.

\section{Proliferation assay}

Proliferation assay was previously described (Puhr et al. 2009).

\section{Cell motility assay}

Cells were cultured in full-growth medium in 24-well cell culture inserts consisting of a transparent, $8 \mu \mathrm{m}$ pore diameter polyethylene terephthalate (PET) membrane (BD Biosciences, Schwechat, Austria). On the next day, medium was replaced with RPMI containing $3 \%$ CSS. Soluble receptors or vehicle and IL-6 were added in the lower chamber. After $48 \mathrm{~h}$, cells in the upper chamber were removed with a cotton swab, whereas the cells that traversed the membrane pores were fixed with cold methanol for $10 \mathrm{~min}$. Membranes were then mounted on microscope slides with Vectashield Mounting Medium with 4'-6'-diamidino2-phenylindole (DAPI) (Vector Labs, Burlingame, CA, USA). Five fields of views per membrane were analysed by fluorescence microscopy with automated cell counting (TissueGnostics, Vienna, Austria).

\section{Scratch assay}

Cells were seeded to near confluence onto 6-well plates and treated as indicated in figure legend. A $10 \mu \mathrm{l}$ tip was used to make a scratch in the confluent layer of cells. After $24 \mathrm{~h}$, pictures at 40 -fold magnification were taken and the remaining free area was measured using the Magic Wand Tool of Adobe Photoshop 7.0.

\section{Adhesion assay}

Ninety-six-well plates were coated with human fibronectin (BD Biosciences) at a final concentration of $2 \mu \mathrm{g} / \mathrm{cm}^{2}$. Cells were seeded in $3 \%$ CSS RPMI in the presence of the soluble receptors or vehicle and IL-6. After up to $2 \mathrm{~h}$ of incubation, cells were washed up to three times with PBS. As an index of cell number, a 3-(4,5-dimethylthiazol-2-yl)-2,5-diphenyltetrazolium bromide (MTT) assay (Biomedica, Vienna, Austria) was performed on the remaining cells according to the manufacturer's protocol. To avoid artefacts due to changes in cell viability, values were normalised to the values obtained from cells equally treated but not washed.

\section{Western blot analysis}

Cells were processed for western blot analyses as previously described (Cavarretta et al. 2007).

\section{Statistical analysis}

All experiments were repeated at least three times. RT-PCR and ELISA assays were repeated twice. The SPSS 12.0 program (Chicago, IL, USA) was used for statistical evaluation and the Mann-Whitney $U$ test was used for the assessment of statistical significance.

\section{Results}

\section{sIL-6R and sgp130 levels in PC cell lines}

We initially tested different prostate cell lines for their ability to release the sIL-6R and the soluble gp130 receptors. We included the non-cancerous cell lines EP156T and BPH-1, the androgen-sensitive LNCaP, LAPC4 and 22Rv1, and the androgen-independent PC3 and Du145 PC cell lines. 
All these cells expressed the mIL-6R, as verified by RT-PCR (data not shown). We found that all cell lines secreted both soluble receptors to a different extent (Tables 1 and 2). Amounts of sIL-6R released by the LAPC4 cells are extremely low, sometimes in the same range of those measured in the culture medium (data not shown). Therefore, we considered LAPC4 cells basically sIL-6R-negative. The addition of IL-6 increased the levels of sgp130 in LNCaP but not in LAPC4.

Interestingly, LNCaP-high passage (LNCaP-HP) cells released a much higher amount of both soluble receptors. We chose for our next experiments two sIL-6R-positive cell lines known to respond differently to the cytokine: LNCaP cells that are growth-inhibited (Hobisch et al. 2001) and Du145 cells that are growth-stimulated by the cytokine (Onuma et al. 2003).

\section{sIL-6R mediates an anti-proliferative effect of IL-6 in different PC cells}

To unmask a possible specific role of the different IL-6Rs on cell proliferation, we applied four approaches, illustrated in Figs 1-4.

We first analysed the effect of the cytokine on ${ }^{3} \mathrm{H}$-thymidine incorporation after specifically inhibiting IL-6TS by pretreating the cells with increasing doses of sgp130. In this model, IL-6 increased proliferation of both LNCaP and Du145 cells by 20 and $40 \%(* P<0.05)$ respectively (Fig. $1 \mathrm{~A}$ and $\mathrm{B}$ ). When applying this method to LNCaP-HP cells, the effect of inhibiting IL-6TS was even more pronounced (60\%), probably due to the higher levels of sIL-6R released by the cell line at this stage (Fig. 1C). When the values of ${ }^{3} \mathrm{H}$-thymidine incorporation from sgp130/ IL-6-treated cells were expressed as a percentage of values from vehicle/IL-6-treated cells, it became evident that suppression of IL-6TS abrogates the

Table 1 Soluble interleukin-6 receptor (sIL-6R) levels in prostate cell lines

\begin{tabular}{lc}
\hline Cell line & $\begin{array}{c}\text { pg slL-6R/2 ml per } 3 \text { days } \\
\text { per } \mathbf{1 0}^{\mathbf{6}} \text { cells }(\text { mean } \pm \text { s.E.M.) }\end{array}$ \\
\hline LAPC4 & $19.88 \pm 10.04$ \\
22Rv1 & $35.64 \pm 13.51$ \\
Du145 & $170.18 \pm 120.57$ \\
BPH-1 & $208.53 \pm 41.61$ \\
EP156T & $246.42 \pm 8.12$ \\
LNCaP & $323.63 \pm 73.42$ \\
PC3 & $445.17 \pm 282.58$ \\
LNCaP-HP & $1363.16 \pm 183.11$ \\
\hline
\end{tabular}

asensitivity: $5 \mathrm{pg} / \mathrm{ml}$.
Table 2 sgp130 levels in prostate cell lines under basal conditions and after interleukin-6 (IL-6) treatment

\begin{tabular}{|c|c|c|}
\hline Cell line & & $\begin{array}{c}\text { pg sgp } 130 / 2 \mathrm{ml} \\
\text { per } 3 \text { days per } \\
10^{6} \text { cells } \\
\left(_{\text {mean } \pm \text { S.E.M. })^{a}}\right.\end{array}$ \\
\hline 22Rv1 & & $45.76 \pm 23.95$ \\
\hline LAPC4 & & $94.68 \pm 11.87$ \\
\hline EP156T & & $143.63 \pm 8.93$ \\
\hline PC3 & & $391.07 \pm 95.44$ \\
\hline LNCaP & & $452.74 \pm 33.42$ \\
\hline Du145 & & $528.28 \pm 77.15$ \\
\hline LNCaP-HP & & $930.86 \pm 129.70$ \\
\hline Cell line & Treatment & $\begin{array}{c}\text { Relative expression (\%) } \\
\text { of sgp } 130 / 2 \mathrm{ml} \\
\text { per } 3 \text { days per } \\
10^{6} \text { cells (mean } \pm \text { S.E.M.) }\end{array}$ \\
\hline LNCaP & & $100 \pm 8.46$ \\
\hline LNCaP & $5 \mathrm{ng} / \mathrm{ml} \mathrm{IL-6}$ & $147.24 \pm 9.60$ \\
\hline LAPC4 & & $100 \pm 1.64$ \\
\hline LAPC4 & $25 \mathrm{ng} / \mathrm{ml}$ IL-6 & $98.40 \pm 1.89$ \\
\hline
\end{tabular}

aSensitivity: $15 \mathrm{pg} / \mathrm{ml}$.

anti-proliferative effect exerted by the cytokine on LNCaP-HP cells (Fig. 1D). The effect is sgp130 dose-dependent.

In the second approach, we investigated the effect of adding increasing doses of sIL-6R to both LNCaP and Du145 cells prior to exposure to IL-6. In both cases, we measured an increased IL-6-induced proliferation (Fig. 2A and B). Concentrations up to $100 \mathrm{ng} / \mathrm{ml}$ sIL-6R did not further increase proliferation (data not shown). Thus, both inhibition of IL-6TS and increase of sIL-6R levels caused an increase of proliferation.

In order to facilitate the interpretation of these results, we decided to remove any contribution of the mIL-6R, therefore unmasking the effect of sIL-6R. In this approach, LNCaP and Du145 cells were transfected with IL-6R siRNA or control siRNA and exposed to sIL-6R and IL-6. Efficacy of siRNA transfection was demonstrated by RT-PCR (Fig. 3A) and sIL-6R ELISA (Fig. 3B). sIL-6R secretion decreased by 70 and $90 \%$ in LNCaP and Du145 cells respectively, transfected with $25 \mathrm{nM}$ IL-6R siRNA compared to cells transfected with control siRNA. Residual receptors were not sufficient to mediate IL-6 effects since the cytokine failed to decrease proliferation of LNCaP cells (Fig. 3C). Transfected cells were thus treated with increasing doses of sIL-6R and IL-6. Again, in the presence of the mIL-6R, i.e. in cells transfected with control siRNAs, we could observe an increase of proliferation when the cells were exposed to the sIL-6R. However, 

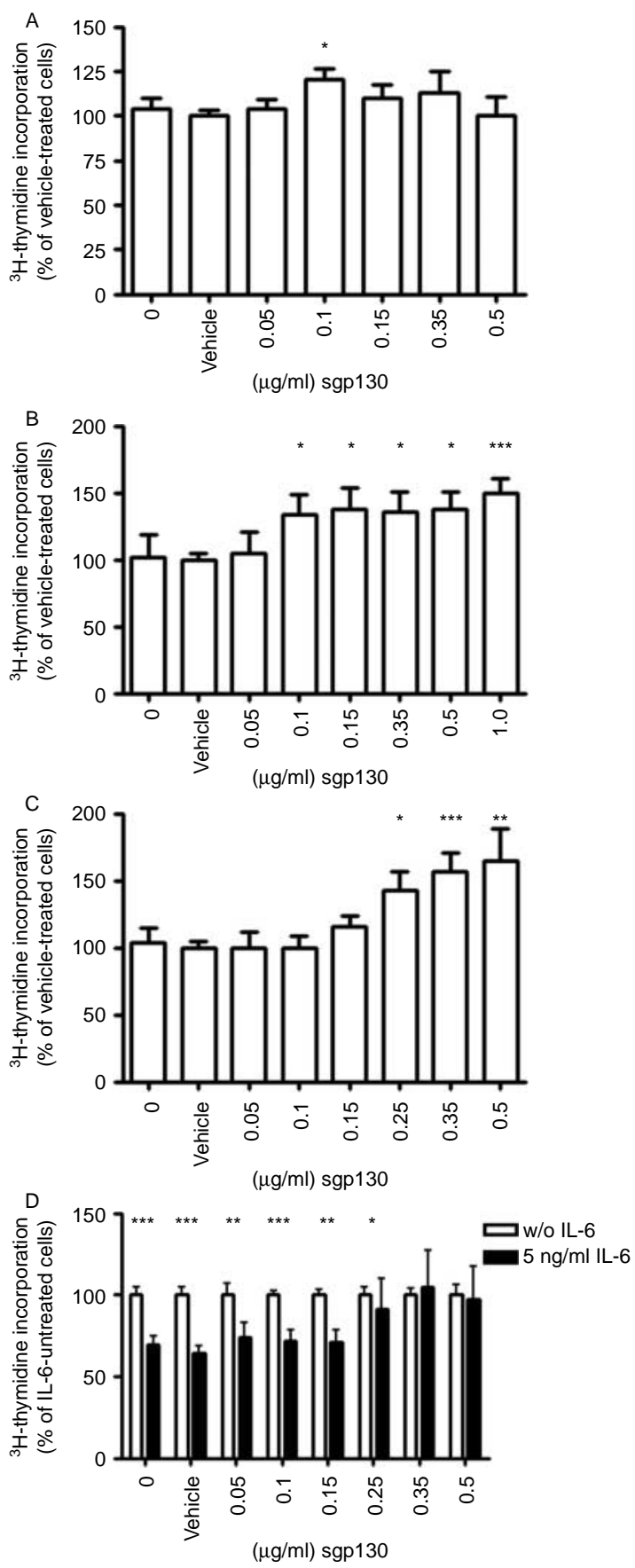

Figure 1 Addition of sgp130 reveals an anti-proliferative effect of IL-6TS in LNCaP and Du145 cells. LNCaP (A), Du145 (B) and LNCaP-HP $(C)$ cells were treated with increasing doses of sgp130, as indicated, and exposed to IL-6. Proliferation was measured by ${ }^{3} \mathrm{H}$-thymidine incorporation and values, expressed as mean \pm S.E.M., were referred as a percentage of vehicletreated samples. (D) The effect of IL-6 on LNCaP-HP cell proliferation was assessed in the absence or presence of increasing doses of sgp130. Values, expressed as mean \pm S.E.M., are referred as a percentage of IL-6-untreated samples ${ }^{\star} P<0.05 ;{ }^{\star \star} P<0.01 ;{ }^{\star \star \star} P<0.001$. after transfection with IL-6R siRNA and exposure to sIL-6R, IL-6 treatment decreased proliferation by $30 \%$ in $\mathrm{LNCaP}$ cells $(* * P<0.01)$ and failed to increase proliferation of Du145 cells (Fig. 3D and E). Thus, it seems that sIL-6R mediates an anti-proliferative effect of the cytokine.

To further confirm this hypothesis, we used LAPC4 cells as a negative control for sIL-6R, as mentioned above. These cells also express lower levels of IL-6R mRNA compared to the other PC cell lines considered (data not shown). Addition of IL-6 to sIL-6R-pretreated LAPC4 cells resulted in a $25 \%$ decrease of proliferation $(* * P<0.01$; Fig. 4). The results were confirmed by counting the number of cells (data not shown).

From this set of experiments, we conclude that sIL-6R mediates an anti-proliferative effect of the cytokine in at least three PC cell lines that are known to respond differently to IL-6. This effect can be masked by the presence and activation of the mIL-6R.
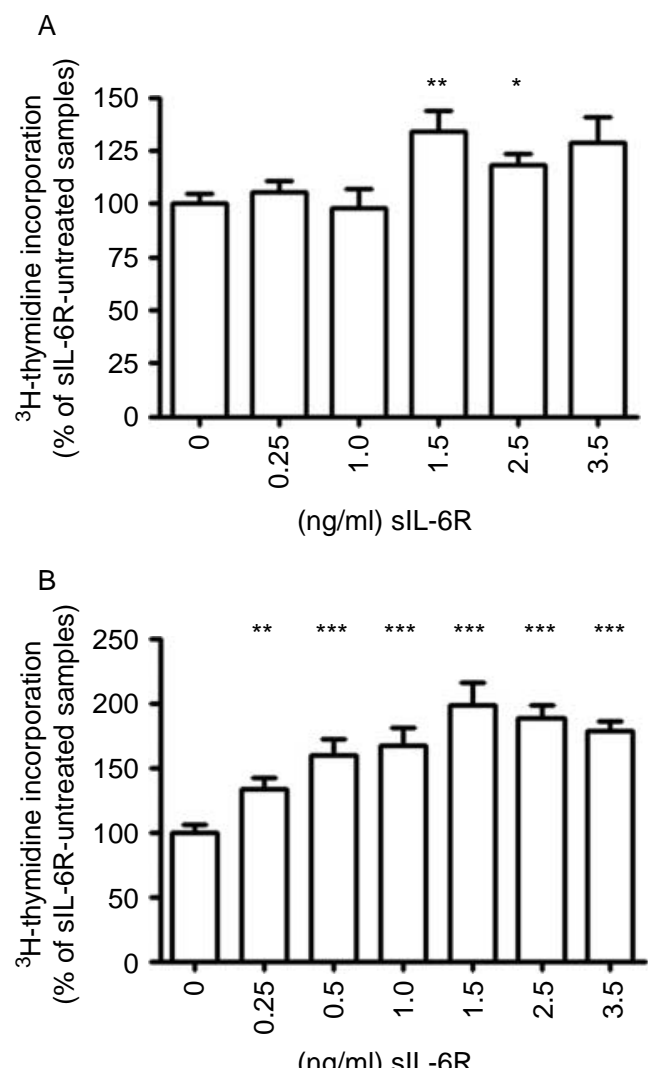

Figure 2 Addition of sIL-6R and IL-6 induces proliferation in LNCaP and Du145 cells. LNCaP (A) and Du145 (B) cells were exposed to increasing doses of sIL-6R, as indicated, prior to treatment with IL-6. Proliferation was measured by ${ }^{3} \mathrm{H}$-thymidine incorporation and values, expressed as mean \pm S.E.M., were referred as a percentage of SIL-6R-untreated samples. ${ }^{\star} P<0.05 ;{ }^{\star \star} P<0.01 ;{ }^{\star \star \star} P<0.001$. 


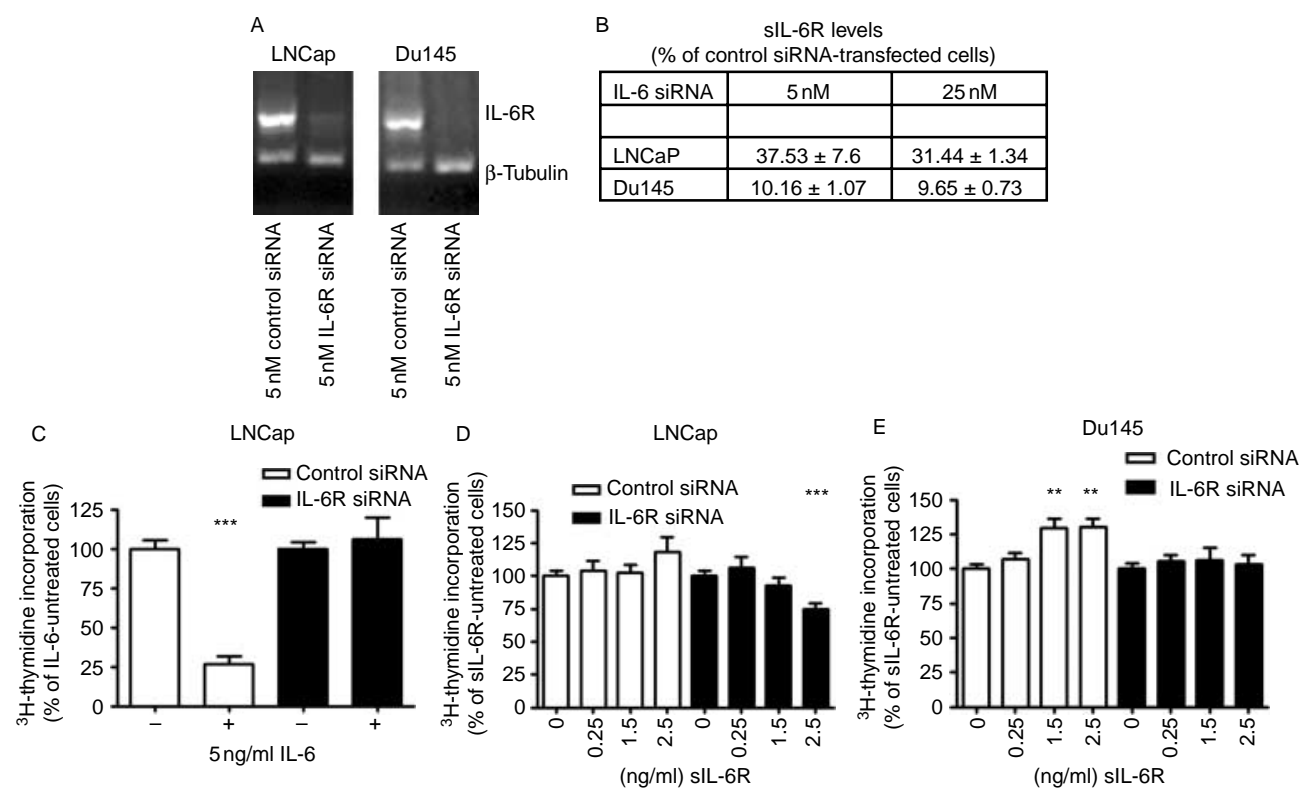

Figure 3 Removal of the contribution of membrane IL-6R by siRNA confirms the anti-proliferative effect of IL-6TS. (A) LNCaP and Du145 were transfected with $5 \mathrm{nM}$ siRNA against IL-6R or equal amounts of control siRNA. RT-PCR was performed to confirm knockdown of IL-6R mRNA. $\beta$-Tubulin was used as a loading control. (B) LNCaP and Du145 were transfected with 5 or $25 \mathrm{nM}$ siRNA against IL-6R or control siRNA, as indicated. Reduction of sIL-6R protein levels was assessed by sIL-6R ELISA. (C) LNCaP were transfected with $25 \mathrm{nM}$ siRNA against IL-6R or control siRNA. Proliferation was measured by ${ }^{3} \mathrm{H}$-thymidine incorporation in the absence or presence of IL-6. LNCaP (D) and Du145 (E) were transfected with $25 \mathrm{nM}$ siRNA against IL-6R or control siRNA and exposed to increasing doses of sIL-6R prior to treatment with IL-6. Proliferation was measured by ${ }^{3} \mathrm{H}$-thymidine incorporation and values, expressed as mean \pm S.E.M., were referred as a percentage of sIL-6R-untreated samples. ${ }^{* \star} P<0.01 ;{ }^{* \star} P<0.001$.

\section{Addition of IL-6 and sIL-6R increases motility and migration of PC cells and decreases cell adhesion}

Based on the higher incidence of PC relapse in patients with increased preoperative levels of sIL-6R and IL-6, we considered a possible involvement of IL-6TS in

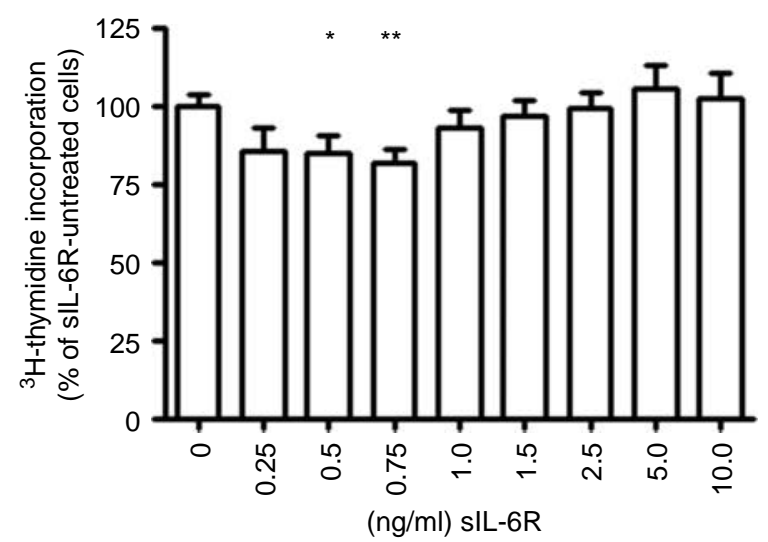

Figure 4 Addition of sIL-6R to LAPC4 mediates an antiproliferative effect of IL-6. LAPC4 were treated with increasing doses of sIL-6R and exposed to IL-6, as indicated. Proliferation was measured by ${ }^{3} \mathrm{H}$-thymidine incorporation. The values were referred as a percentage of slL-6R-untreated samples (mean 土S.E.M). ${ }^{\star} P<0.05 ;{ }^{\star \star} P<0.01$. processes relevant to tumour metastases. To this aim, as an index of cell motility, we tested the ability of LNCaP, Du145 and LAPC4 cells to migrate through an $8 \mu \mathrm{m}$ pore diameter membrane after exposure to IL-6 in the presence of sgp130, vehicle or sIL-6R. In particular, we found that the number of migrated cells was significantly decreased when LNCaP and Du145 cells were exposed to sgp130 and IL-6 compared to cells exposed to the vehicle and IL-6 (Fig. 5A and B). Consistent with this finding, migration of LAPC4 cells was facilitated in the presence of sIL-6R and IL-6 compared to cells exposed to IL-6 only (Fig. 5C). Afterwards, we applied the scratch assay. Consistently, Du145 cells migrated less after inhibition of IL-6TS (Fig. 6). Unfortunately, LNCaP and LAPC4 cells could not be used in this kind of assay due to their characteristic to form clusters.

Then we investigated the involvement of the sIL-6R on cell adhesion. To this aim, Du145 cells were seeded on fibronectin substrate in the presence of IL- 6 alone or along with increasing doses of sIL-6R. We found that the presence of sIL-6R caused a 25\% decrease in adhesion to the substrate (Fig. 7). However, when the cells were pre-exposed to the IL-6TS inhibitor sgp130, there was no significant difference between sIL-6R-untreated 
A

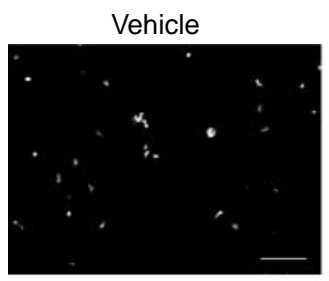

$0.25 \mu \mathrm{g} / \mathrm{ml}$ sgp130

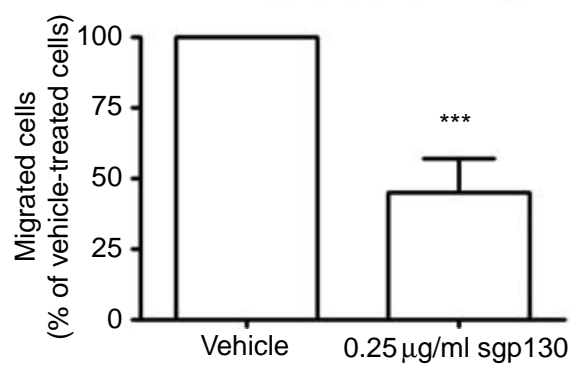

B

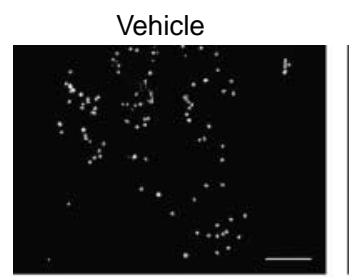
$0.25 \mu \mathrm{g} / \mathrm{ml} \mathrm{sgp} 130$
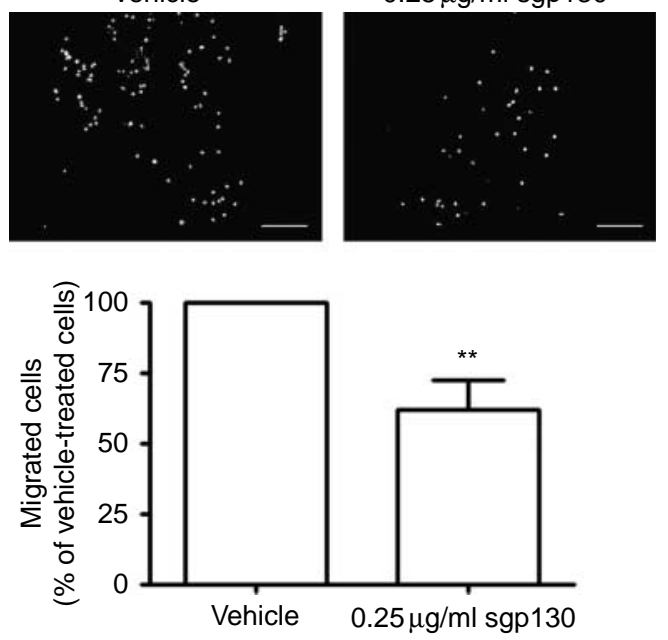

C
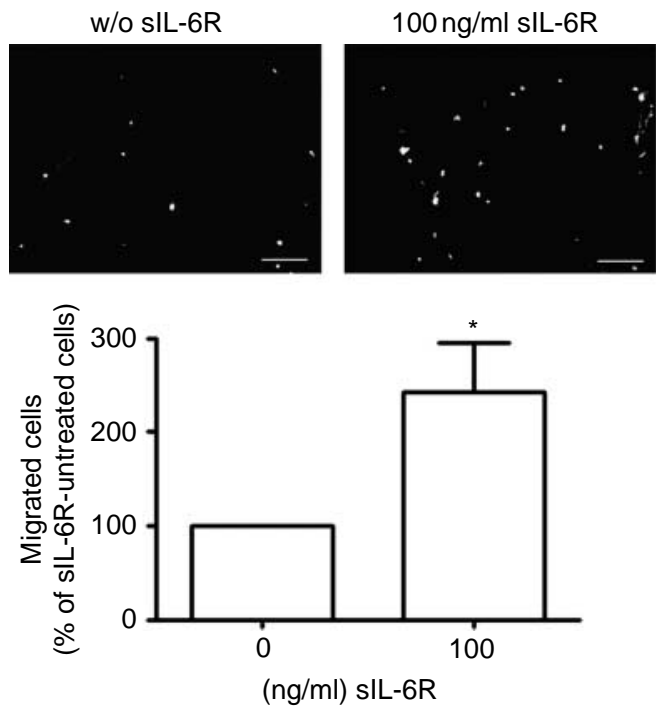

and -treated cells. A significantly decreased adhesion in the presence of IL-6 and sIL-6R was also observed when LAPC4 were used (data not shown).

We concluded that sIL-6R has a role in decreasing adhesion and increasing motility and migration of PC cells, events that represent crucial initial steps in the formation of metastases.

\section{IL-6TS decreases maspin expression in PC cell lines}

In order to investigate the mechanism by which IL-6TS may promote the spread of PC cells, we looked at the expression of maspin, a tumour suppressor recently shown to be involved in regulation of cell adhesion and motility in PC (Sheng et al. 1996, Abraham et al. 2003, Ngamkitidechakul et al. 2003). We found that the noncancerous epithelial prostate cells BPH-1 and EP156T express higher basal levels of the protein compared to the PC cell lines tested (Fig. 8). Interestingly, we found that IL-6 decreased the expression of maspin in Du145, LNCaP and LAPC4 cells, but not in EP156T cells (Fig. 9A-C and F respectively). Inhibition of IL-6TS prior to exposure to IL- 6 antagonised the decrease of maspin in LNCaP (Fig. 9E) and abrogated it in Du145 cells (Fig. 9D). Finally, a further decrease of maspin was observed in LAPC4 cells after exposure to sIL-6R and to IL-6. The effect is sIL-6R dose-dependent (Fig. 10). These results contribute to understanding the mechanisms through which the cytokine may promote PC progression and demonstrate the involvement of IL-6TS in the downregulation of the tumour suppressor maspin.

\section{Discussion}

A pathophysiological role of IL-6 in the progression of PC has been suggested and supported by several in vitro and in vivo investigations leading to the idea that anti-cytokine therapies could represent a promising attempt to slow down the evolution of this disease. However, in vitro and preclinical studies have yielded contrasting responses to IL-6 or anti-IL-6 antibodies. Thus, the outcome of IL-6-targeting therapies may be unpredictable also in PC patients, ranging from a lack of response to beneficial or detrimental effects.

Figure 5 IL-6TS increases cell motility. Cells were seeded onto cell culture inserts, as described in materials and methods.

LNCaP (A) and Du145 (B) were exposed to IL-6 after treatment with sgp130 or vehicle. LAPC4 (C) were exposed to IL-6 in the presence or absence of $100 \mathrm{ng} / \mathrm{ml}$ slL-6R. Motility was measured by counting cells that migrated through the membrane. Scale bar is $200 \mu \mathrm{m}$. Values are expressed as mean \pm S.E.M. ${ }^{\star} P<0.05 ;{ }^{\star \star} P<0.01 ;{ }^{\star \star \star} P<0.001$. 

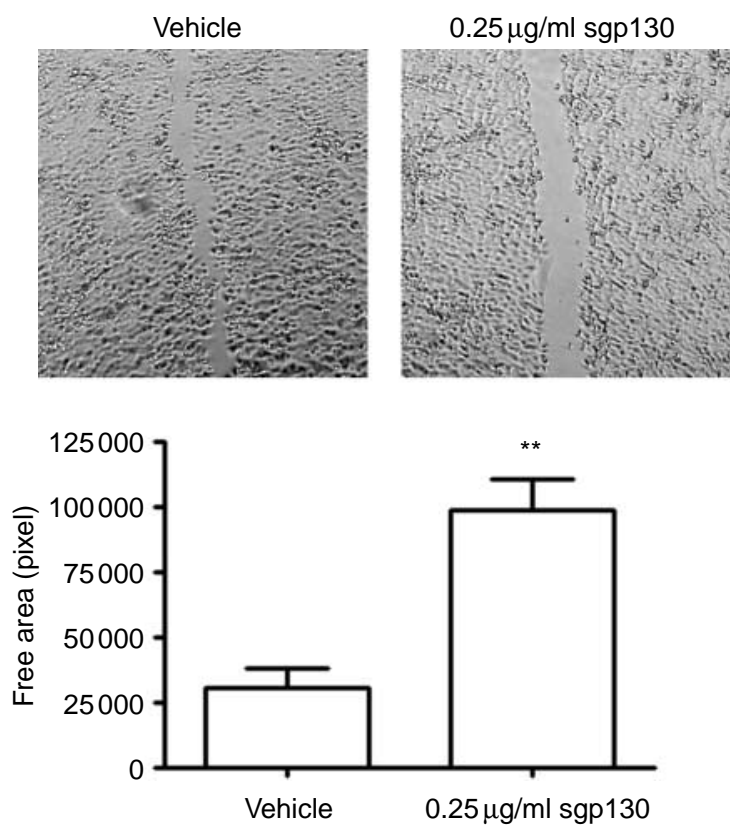

Figure 6 Blocking of IL-6TS decreases Du145 cell migration. Du145 cells were treated with IL-6 in the presence of sgp130 or vehicle. At cell confluence, a scratch was performed using a $10 \mu \mathrm{ltip}$. After $24 \mathrm{~h}$ remaining free area was measured. Values are expressed as mean \pm S.E.M. ${ }^{\star *} P<0.01$.

In order to better understand the mechanisms underlying the different responses to the cytokine, we focused our attention on IL-6Rs that represent the first element in the cascade of signalling activated by IL-6. In particular, we investigated which roles of IL-6 may be specifically ascribed to IL-6TS rather than to the classical IL-6 signalling in PC cells.

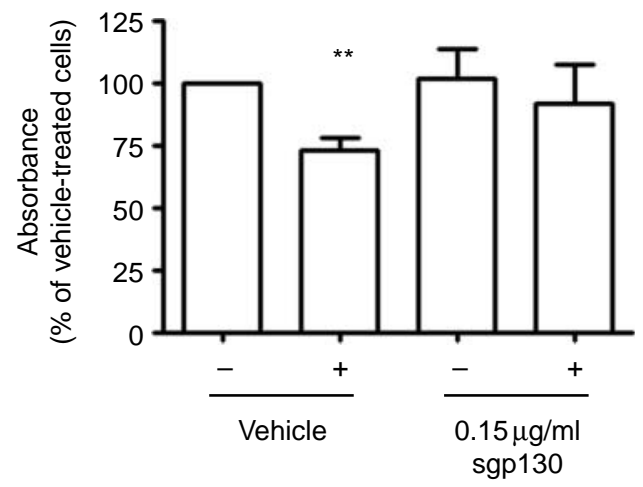

$100 \mathrm{ng} / \mathrm{ml}$ slL-6R

Figure 7 Addition of SIL-6R and IL-6 decreases adhesion to fibronectin, which can be inhibited by sgp130. Du145 cells were seeded on fibronectin substrate in the presence of sgp130 or vehicle and treated with IL- 6 in the absence or presence of sIL-6R. Values are expressed as mean \pm S.E.M. ${ }^{\star \star} P<0.01$.

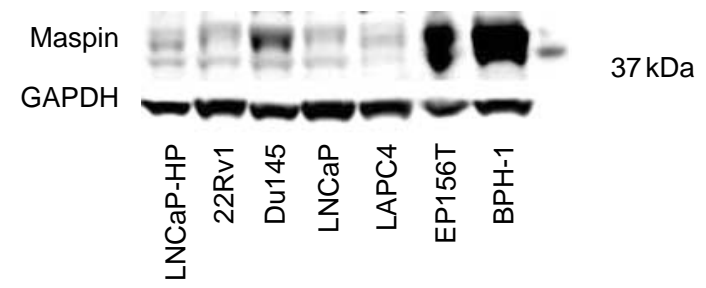

Figure 8 Expression levels of maspin in cancerous and noncancerous prostate cells. Equal amounts of protein lysates from the non-cancerous BPH-1 and EP156T and the cancerous LAPC4, LNCaP, Du145, PC3, 22Rv1 and LNCaP-HP cells were analysed for maspin expression levels by western blotting. GAPDH served as a loading control.

We used PC cells that express both membrane and soluble receptors as a natural mIL-6R $+/$ sIL- $6 \mathrm{R}+$ model and cells that possess virtually only the mIL-6R as a natural mIL-6R +/sIL-6R - model. In addition, by modifying the levels of the receptors, we created two additional models: mIL-6R $+/$ sIL-6R - , obtained by specifically inhibiting IL-6TS in LNCaP and Du145 cells by sgp130; and mIL-6R -/sIL-6R + , in which the sIL-6R has been added to the cells after knockdown of both soluble and membrane IL-6Rs. By using these different approaches, we were able to attribute the capacity to mediate an anti-proliferative effect of IL-6 to the sIL-6R, regardless the cell line used. In particular, proliferation was increased by IL-6 in both LNCaP and Du145 cells after inhibition of IL-6TS by sgp130. LAPC4 cells were growth inhibited by IL-6 in the presence of sIL-6R. Based on this finding, we expected that the addition of IL-6 and sIL-6R would have caused a decrease of proliferation also in $\mathrm{LNCaP}$ and Du145 cells; instead, we measured a significant increase of proliferation. Several hypotheses might explain this apparent discrepancy; the possible existence of a still unknown complex containing both mIL-6R and sIL-6R is intriguing. This complex would be responsible for an increase of proliferation whenever the sIL-6R is increased. On the other hand, the complex IL-6/sIL-6R/gp130, already known to activate only IL-6TS, would be responsible for a decreased proliferation. The final result would be a sum of the two events. Thus, the mIL-6R would mediate a proliferative effect of the cytokine in competition with IL-6TS.

Further complexity was found by the fact that IL-6 increases the levels of sgp130 released from LNCaP cells. This effect is probably mediated by the sIL-6R in that IL-6 is not effective in LAPC4 (Table 2) nor in cells with low levels of sIL-6R (data not shown). These data further underline the relevance of the relative content of sIL-6R and mIL-6R for a specific effect of the cytokine. Consistent with our finding, a decrease of proliferation 

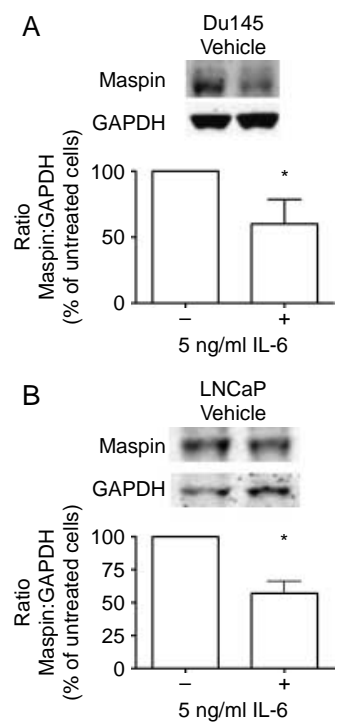

C
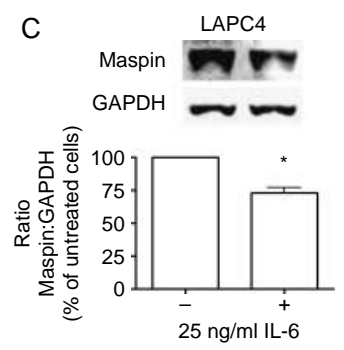

Du145
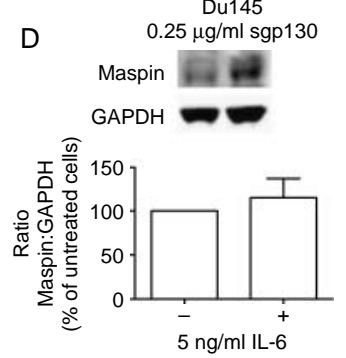

$E$

LNCaP

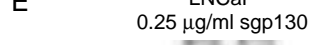

Maspin

GAPDH
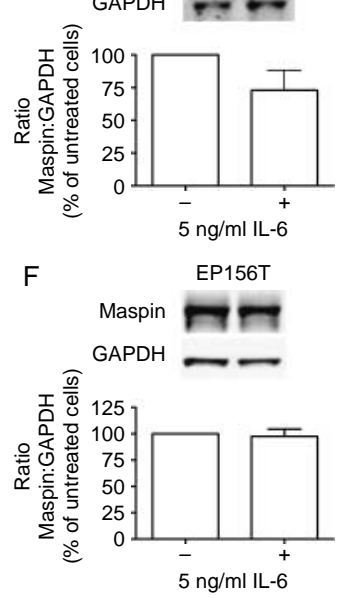

by IL-6TS has also been recently observed in a pleomorphic malignant fibrous histiocytoma cell line (Nakanishi et al. 2004). A fusion protein consisting of human IL-6 and human sIL-6R was also shown to reduce proliferation of $\mathrm{B} 16$ melanoma (Ozbek et al. 2001) and F10.9 cells (Wagley et al. 2007).

At this stage, the possibility of interactions between sIL-6R and other not yet identified factors cannot be excluded and the situation in vivo seems to be more complex. In this regard, we cross-refer to Knupfer \& Preiss (2008) for an interesting discussion on the possible agonistic and non-agonistic properties of sIL-6R.

Although high levels of IL-6 are considered indicators of bad prognosis and consistently found associated with metastases, very little data showing a direct link between IL-6 and metastatogenesis in different malignancies are known (Kanazawa et al. 2007, Studebaker et al. 2008); surprisingly, no reports are so far available in the field of PC. As previously mentioned, an association between the levels of sIL-6R in PC patients before prostatectomy and higher probability to develop metastases has been found (Kattan et al. 2003, Shariat et al. 2004, 2008). We therefore turned our attention to the possible involvement of IL-6/sIL-6R in mechanisms responsible for cancer dissemination to secondary organs. One event relevant to invasion and metastasis formation is the increased motility. Interestingly, we found that activation of IL-6TS resulted in increased motility and migration of PC cells. In accordance with this, a role for IL-6 in promoting migration and invasion has been very recently reported also in breast tumour cells (Walter et al. 2009).

Changes in adhesive properties to extracellular matrix (ECM) components also play a critical role in the process of tumour dissemination being an essential prerequisite for increased acquisition of movement of the cells. We measured an IL-6/sIL-6R-dependent decrease of attachment of Du145 and LAPC4 cells to one of the major components of the prostate ECM. This is the first evidence that IL-6TS activation may promote PC dissemination.

In order to clarify through which mechanism IL-6 could facilitate the spread of PC cells, we considered the tumour suppressor gene maspin, a $42 \mathrm{kDa}$ serine protease inhibitor, which has been recently proven to

Figure 9 Maspin expression is decreased by IL-6. This effect can be antagonised by the addition of sgp130. Cells were treated for $48 \mathrm{~h}$ with or without IL-6 in the absence or presence of sgp130, as indicated. Maspin and GAPDH (loading control) expression levels were analysed by western blotting and quantified densitometrically. Values are expressed as mean \pm S.E.M. ${ }^{\star} P<0.05$. 


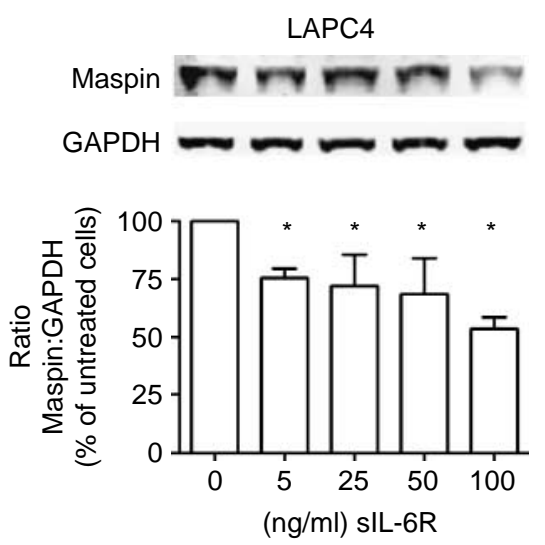

Figure 10 Addition of sIL-6R and IL-6 reduces maspin expression levels in LAPC4. LAPC4 were treated with increasing doses of sIL-6R prior to exposure to IL-6. Treatment lasted for $48 \mathrm{~h}$. Equal amounts of protein lysates were analysed for maspin and GAPDH (loading control) expression by western blotting. Values are expressed as mean \pm S.E.M. ${ }^{*} P<0.05$.

block tumour invasion, stimulates cell adhesion and blocks angiogenesis in breast and PCs (Zou et al. 1994, Sheng et al. 1996, Zhang et al. 2000, Abraham et al. 2003, Cher et al. 2003, Ngamkitidechakul et al. 2003, Denk et al. 2007). In particular, Du145, LNCaP and PC3 cells were shown to be inhibited in terms of invasion and motility when treated with exogenous recombinant maspin (Schaefer \& Zhang 2003). Most importantly, in vivo evidence that maspin inhibits metastatogenesis was provided by Luo et al. (2007); they demonstrated that maspin-negative PC cells from TRAMP mice give rise to numerous liver metastases in nude male mice, whereas forced maspin expression in the same cells dramatically reduced their metastatic activity. Yet, athymic nude mice inoculated with PC3overexpressing maspin developed significantly fewer and less destructive bone metastases than parental PC3 (Hall et al. 2008). We demonstrate that IL-6 decreases the expression of maspin in Du145, LAPC4 and LNCaP PC cells but not in the non-cancerous prostate cells. This finding provides a mechanistic explanation for the pathogenic role of IL-6 in PC progression.

Interestingly, inhibition of IL-6TS antagonised the effect of the cytokine on maspin levels suggesting the main role for the sIL-6R in mediating this effect of IL-6. The soluble gp130 may regulate maspin expression also in the absence of the IL-6 (data not shown) confirming the already proposed binding of sgp130 to other ligands/soluble receptors (MonteroJulian et al. 1997, Jones et al. 2001). However, in the presence of the cytokine, affinity of sgp130 for IL-6TS prevails. The role of IL-6TS on maspin regulation is further supported by experiments showing that the levels of maspin decrease in LAPC4 cells after exposure to sIL-6R and IL-6. Interestingly, an increased attachment on fibronectin-coated plates by Du145 cells overexpressing maspin was also reported (Abraham et al. 2003, Tahmatzopoulos et al. 2005).

Maspin expression is reduced in prostate tumours and cancer cell lines compared to normal prostate epithelial cells (Sheng et al. 1996). Consistent with this, we also measured dramatically higher basal levels of maspin in the non-cancerous prostate epithelial cells compared to PC cells. Decreased expression of maspin has been shown to correlate with breast and PC progression (Maass et al. 2000, Pierson et al. 2002). In particular, in human primary PCs, maspin expression consistently appears to be down-regulated at the critical transition from non-invasive, low-grade disease to highly invasive, high-grade PC (Pierson et al. 2002).

With respect to possible signalling pathways activated by IL-6TS, we have considered phosphorylation of STAT3, ERK1/2 and STAT1 in cells in which IL-6TS had been previously enhanced or inhibited. Neither signalling pathway was found to be specifically activated by IL-6TS (data not shown). To the best of our knowledge, there is so far nothing known about a signalling pathway that can be switched on/off only by IL-6/sIL-6R. We believe that specificity to the IL-6TS may be given by other cytokines and/or receptors. Future investigations in these directions are planned.

The current work showing a role of IL-6TS in decreasing adhesion and increasing motility and migration along with its effect on the inhibition of maspin strongly supports the hypothesis that the sIL-6R may have an important role in metastasis formation. Therefore, specific targeting of IL-6TS in PC patients might represent an elegant way to refine the currently available experimental anti-IL-6 therapies. It would be worth in the future to determine whether the sgp130 plasma levels, in addition to those of sIL-6R and IL-6, are altered in PC patients with a worse prognosis. This information may help to identify those patients who could benefit from the anti-cytokine therapy.

\section{Declaration of interest}

The authors declare no conflict of interest that could be perceived as prejudicing the impartiality of the research reported.

\section{Funding}

This work was supported by Medizinische Forschungsförderung Innsbruck (MFI) (grant number: 9401). Publication costs and open access option were funded by the Fonds National de la Recherche Luxembourg. 


\section{Acknowledgements}

We thank Thomas Hensle for kindly providing editorial assistance.

\section{References}

Abraham S, Zhang W, Greenberg N \& Zhang M 2003 Maspin functions as tumor suppressor by increasing cell adhesion to extracellular matrix in prostate tumor cells. Journal of Urology 169 1157-1161.

Becker C, Fantini MC, Schramm C, Lehr HA, Wirtz S, Nikolaev A, Burg J, Strand S, Kiesslich R, Huber S et al. 2004 TGF-beta suppresses tumor progression in colon cancer by inhibition of IL-6 trans-signaling. Immunity $\mathbf{2 1}$ 491-501.

Cavarretta IT, Neuwirt H, Untergasser G, Moser PL, Zaki MH, Steiner H, Rumpold H, Fuchs D, Hobisch A, Nemeth JA et al. 2007 The antiapoptotic effect of IL-6 autocrine loop in a cellular model of advanced prostate cancer is mediated by Mcl-1. Oncogene 26 2822-2832.

Cher ML, Biliran HR Jr, Bhagat S, Meng Y, Che M, Lockett J, Abrams J, Fridman R, Zachareas M \& Sheng S 2003 Maspin expression inhibits osteolysis, tumor growth, and angiogenesis in a model of prostate cancer bone metastasis. PNAS 100 7847-7852.

Denk AE, Bettstetter M, Wild PJ, Hoek K, Bataille F, Dietmaier W \& Bosserhoff AK 2007 Loss of maspin expression contributes to a more invasive potential in malignant melanoma. Pigment Cell Research 20 112-119.

Friedman J, Dunn RL, Wood D, Vaishampayan U, Wu A, Bradley D, Montie J, Sarkar FH, Shah RB \& Hussain M 2008 Neoadjuvant docetaxel and capecitabine in patients with high risk prostate cancer. Journal of Urology 179 911-915 discussion 915-916.

George DJ, Halabi S, Shepard TF, Sanford B, Vogelzang NJ, Small EJ \& Kantoff PW 2005 The prognostic significance of plasma interleukin-6 levels in patients with metastatic hormone-refractory prostate cancer: results from cancer and leukemia group B 9480. Clinical Cancer Research 11 1815-1820.

Hall DC, Johnson-Pais TL, Grubbs B, Bernal R, Leach RJ \& Padalecki SS 2008 Maspin reduces prostate cancer metastasis to bone. Urologic Oncology 26 652-658.

Hayward SW, Dahiya R, Cunha GR, Bartek J, Deshpande N \& Narayan P 1995 Establishment and characterization of an immortalized but non-transformed human prostate epithelial cell line: BPH-1. In Vitro Cellular \& Developmental Biology. Animal 31 14-24.

Hobisch A, Ramoner R, Fuchs D, Godoy-Tundidor S, Bartsch G, Klocker H \& Culig Z 2001 Prostate cancer cells (LNCaP) generated after long-term interleukin 6 (IL-6) treatment express IL-6 and acquire an IL-6 partially resistant phenotype. Clinical Cancer Research 7 2941-2948.
Jones SA, Horiuchi S, Topley N, Yamamoto N \& Fuller GM 2001 The soluble interleukin 6 receptor: mechanisms of production and implications in disease. FASEB Journal 15 43-58.

Jostock T, Mullberg J, Ozbek S, Atreya R, Blinn G, Voltz N, Fischer M, Neurath MF \& Rose-John S 2001 Soluble gp130 is the natural inhibitor of soluble interleukin-6 receptor transsignaling responses. European Journal of Biochemistry 268 160-167.

Kallen KJ 2002 The role of transsignalling via the agonistic soluble IL-6 receptor in human diseases. Biochimica et Biophysica Acta 1592 323-343.

Kanazawa T, Nishino H, Hasegawa M, Ohta Y, Lino Y, Ichimura K \& Noda Y 2007 Interleukin-6 directly influences proliferation and invasion potential of head and neck cancer cells. European Archives of Oto-Rhino-Laryngology 264 815-821.

Kang KW, Wagley Y, Kim HW, Pokharel YR, Chung YY, Chang IY, Kim JJ, Moon JS, Kim YK, Nah SY et al. 2007 Novel role of IL-6/sIL-6R signaling in the expression of inducible nitric oxide synthase (iNOS) in murine B16, metastatic melanoma clone F10.9, cells. Free Radical Biology \& Medicine 42 215-227.

Kattan MW, Shariat SF, Andrews B, Zhu K, Canto E, Matsumoto K, Muramoto K, Muramoto M, Scardino PT, Ohori M et al. 2003 The addition of interleukin-6 soluble receptor and transforming growth factor beta 1 improves a preoperative nomogram for predicting biochemical progression in patients with clinically localized prostate cancer. Journal of Clinical Oncology 21 3573-3579.

Knupfer H \& Preiss R 2008 sIL-6R: more than an agonist? Immunology and Cell Biology 86 87-91.

Kogan I, Goldfinger N, Milyavsky M, Cohen M, Shats I, Dobler G, Klocker H, Wasylyk B, Voller M, Aalders T et al. 2006 hTERT-immortalized prostate epithelial and stromal-derived cells: an authentic in vitro model for differentiation and carcinogenesis. Cancer Research 66 3531-3540.

Lassi K \& Dawson NA 2009 Emerging therapies in castrateresistant prostate cancer. Current Opinion in Oncology 21 260-265.

Lin DL, Whitney MC, Yao Z \& Keller ET 2001 Interleukin-6 induces androgen responsiveness in prostate cancer cells through up-regulation of androgen receptor expression. Clinical Cancer Research 7 1773-1781.

Luo JL, Tan W, Ricono JM, Korchynskyi O, Zhang M, Gonias SL, Cheresh DA \& Karin M 2007 Nuclear cytokine-activated IKKalpha controls prostate cancer metastasis by repressing Maspin. Nature 446 690-694.

Maass N, Hojo T, Zhang M, Sager R, Jonat W \& Nagasaki K 2000 Maspin - a novel protease inhibitor with tumorsuppressing activity in breast cancer. Acta Oncologica 39 931-934.

Malinowska K, Neuwirt H, Cavarretta IT, Bektic J, Steiner H, Dietrich H, Moser PL, Fuchs D, Hobisch A \& Culig Z 2009 Interleukin-6 stimulation of growth of prostate 
cancer in vitro and in vivo through activation of the androgen receptor. Endocrine-Related Cancer 16 155-169.

Mitsuyama K, Matsumoto S, Rose-John S, Suzuki A, Hara T, Tomiyasu N, Handa K, Tsuruta O, Funabashi H, Scheller $\mathrm{J}$ et al. 2006a STAT3 activation via interleukin 6 transsignalling contributes to ileitis in SAMP1/Yit mice. Gut 55 1263-1269.

Mitsuyama K, Sata M \& Rose-John S 2006b Interleukin-6 trans-signaling in inflammatory bowel disease. Cytokine \& Growth Factor Reviews 17 451-461.

Montero-Julian FA, Brailly H, Sautes C, Joyeux I, Dorval T, Mosseri V, Yasukawa K, Wijdenes J, Adler A, Gorin I et al. 1997 Characterization of soluble gp130 released by melanoma cell lines: a polyvalent antagonist of cytokines from the interleukin 6 family. Clinical Cancer Research 3 1443-1451.

Mumm JB \& Oft M 2008 Cytokine-based transformation of immune surveillance into tumor-promoting inflammation. Oncogene 27 5913-5919.

Naka T, Nishimoto N \& Kishimoto T 2002 The paradigm of IL-6: from basic science to medicine. Arthritis Research 4 (Suppl 3) S233-S242.

Nakanishi H, Yoshioka K, Joyama S, Araki N, Myoui A, Ishiguro S, Ueda T, Yoshikawa H \& Itoh K 2004 Interleukin-6/soluble interleukin-6 receptor signaling attenuates proliferation and invasion, and induces morphological changes of a newly established pleomorphic malignant fibrous histiocytoma cell line. American Journal of Pathology 165 471-480.

Ngamkitidechakul C, Warejcka DJ, Burke JM, O'Brien WJ $\&$ Twining SS 2003 Sufficiency of the reactive site loop of maspin for induction of cell-matrix adhesion and inhibition of cell invasion. Conversion of ovalbumin to a maspin-like molecule. Journal of Biological Chemistry 278 31796-31806.

Nowell MA, Richards PJ, Horiuchi S, Yamamoto N, Rose-John S, Topley N, Williams AS \& Jones SA 2003 Soluble IL-6 receptor governs IL-6 activity in experimental arthritis: blockade of arthritis severity by soluble glycoprotein 130. Journal of Immunology 171 3202-3209.

Nowell MA, Williams AS, Carty SA, Scheller J, Hayes AJ, Jones GW, Richards PJ, Slinn S, Ernst M, Jenkins BJ et al. 2009 Therapeutic targeting of IL-6 trans signaling counteracts STAT3 control of experimental inflammatory arthritis. Journal of Immunology 182 613-622.

Onuma M, Bub JD, Rummel TL \& Iwamoto Y 2003 Prostate cancer cell-adipocyte interaction: leptin mediates androgen-independent prostate cancer cell proliferation through c-Jun NH2-terminal kinase. Journal of Biological Chemistry 278 42660-42667.

Ozbek S, Peters M, Breuhahn K, Mann A, Blessing M, Fischer M, Schirmacher P, Mackiewicz A \& Rose-John S 2001 The designer cytokine hyper-IL-6 mediates growth inhibition and GM-CSF-dependent rejection of B16 melanoma cells. Oncogene 20 972-979.
Petrylak DP 2007 New paradigms for advanced prostate cancer. Reviews in Urology 19 (Suppl 2) S3-S12.

Pierson CR, McGowen R, Grignon D, Sakr W, Dey J \& Sheng S 2002 Maspin is up-regulated in premalignant prostate epithelia. Prostate 53 255-262.

Puhr M, Santer FR, Neuwirt H, Susani M, Nemeth JA, Hobisch A, Kenner L \& Culig Z 2009 Down-regulation of suppressor of cytokine signaling-3 causes prostate cancer cell death through activation of the extrinsic and intrinsic apoptosis pathways. Cancer Research 69 7375-7384.

Rose-John S 2003 Interleukin-6 biology is coordinated by membrane bound and soluble receptors. Acta Biochimica Polonica 50 603-611.

Rose-John S, Waetzig GH, Scheller J, Grotzinger J \& Seegert D 2007 The IL-6/sIL-6R complex as a novel target for therapeutic approaches. Expert Opinion on Therapeutic Targets 11 613-624.

Schaefer JS \& Zhang M 2003 Role of maspin in tumor metastasis and angiogenesis. Current Molecular Medicine 3 653-658.

Scheller J \& Rose-John S 2006 Interleukin-6 and its receptor: from bench to bedside. Medical Microbiology and Immunology 195 173-183.

Shariat SF, Andrews B, Kattan MW, Kim J, Wheeler TM \& Slawin KM 2001 Plasma levels of interleukin-6 and its soluble receptor are associated with prostate cancer progression and metastasis. Urology $\mathbf{5 8}$ 1008-1015.

Shariat SF, Kattan MW, Traxel E, Andrews B, Zhu K, Wheeler TM \& Slawin KM 2004 Association of pre- and postoperative plasma levels of transforming growth factor beta(1) and interleukin 6 and its soluble receptor with prostate cancer progression. Clinical Cancer Research 10 1992-1999.

Shariat SF, Karam JA, Walz J, Roehrborn CG, Montorsi F, Margulis V, Saad F, Slawin KM \& Karakiewicz PI 2008 Improved prediction of disease relapse after radical prostatectomy through a panel of preoperative bloodbased biomarkers. Clinical Cancer Research 14 3785-3791.

Sheng S, Carey J, Seftor EA, Dias L, Hendrix MJ \& Sager R 1996 Maspin acts at the cell membrane to inhibit invasion and motility of mammary and prostatic cancer cells. PNAS 93 11669-11674.

Sramkoski RM, Pretlow TG II, Giaconia JM, Pretlow TP, Schwartz S, Sy M-S, Marengo SR, Rhim JS, Zhang D \& Jacobberger JW 1999 A new human prostate carcinoma cell line, 22Rv1. In Vitro Cellular \& Developmental Biology. Animal 35 403-409.

Steiner H, Godoy-Tundidor S, Rogatsch H, Berger AP, Fuchs D, Comuzzi B, Bartsch G, Hobisch A \& Culig Z 2003 Accelerated in vivo growth of prostate tumors that up-regulate interleukin-6 is associated with reduced retinoblastoma protein expression and activation of the mitogen-activated protein kinase pathway. American Journal of Pathology 162 655-663. 
Steiner H, Cavarretta IT, Moser PL, Berger AP, Bektic J, Dietrich H, Zaki M, Nakada M, Hobisch A, Nemeth JA et al. 2006 Regulation of growth of prostate cancer cells selected in the presence of interleukin- 6 by the anti-interleukin-6 antibody CNTO 328. Prostate 66 1744-1752.

Studebaker AW, Storci G, Werbeck JL, Sansone P, Sasser AK, Tavolari S, Huang T, Chan MW, Marini FC, Rosol TJ et al. 2008 Fibroblasts isolated from common sites of breast cancer metastasis enhance cancer cell growth rates and invasiveness in an interleukin-6-dependent manner. Cancer Research 68 9087-9095.

Tahmatzopoulos A, Sheng S \& Kyprianou N 2005 Maspin sensitizes prostate cancer cells to doxazosin-induced apoptosis. Oncogene 24 5375-5383.

Trikha M, Corringham R, Klein B \& Rossi JF 2003 Targeted anti-interleukin- 6 monoclonal antibody therapy for cancer: a review of the rationale and clinical evidence. Clinical Cancer Research 9 4653-4665.

Twillie DA, Eisenberger MA, Carducci MA, Hseih WS, Kim WY \& Simons JW 1995 Interleukin-6: a candidate mediator of human prostate cancer morbidity. Urology 45 542-549.
Wagley Y, Yoo YC, Seo HG, Rhee MH, Kim TH, Kang KW, Nah SY \& Oh JW 2007 The IL-6/sIL-6R treatment of a malignant melanoma cell line enhances susceptibility to TNF-alpha-induced apoptosis.

Biochemical and Biophysical Research Communications 354 985-991.

Wallner L, Dai J, Escara-Wilke J, Zhang J, Yao Z, Lu Y, Trikha M, Nemeth JA, Zaki MH \& Keller ET 2006 Inhibition of interleukin-6 with CNTO328, an antiinterleukin-6 monoclonal antibody, inhibits conversion of androgen-dependent prostate cancer to an androgenindependent phenotype in orchiectomized mice. Cancer Research 66 3087-3095.

Walter M, Liang S, Ghosh S, Hornsby PJ \& Li R 2009 Interleukin 6 secreted from adipose stromal cells promotes migration and invasion of breast cancer cells. Oncogene 30 2745-2755.

Zhang M, Volpert O, Shi YH \& Bouck N 2000 Maspin is an angiogenesis inhibitor. Nature Medicine 6 196-199.

Zou Z, Anisowicz A, Hendrix MJ, Thor A, Neveu M, Sheng S, Rafidi K, Seftor E \& Sager R 1994 Maspin, a serpin with tumor-suppressing activity in human mammary epithelial cells. Science 263 526-529. 